\title{
Agent-Based Models of the Corporate Bond Market
}

\author{
Donald J. Berndt \\ University of South Florida \\ 4202 E. Fowler Avenue, CIS 1040 \\ Tampa, FL 33620 \\ $+18139746769$ \\ dberndt@usf.edu
}

\author{
David Boogers \\ FinaMetrics \\ 15310 Amberly Drive, Suite 250 \\ Tampa, FL 33647 \\ $+18134402055$ \\ $\mathrm{db} @$ finametrics.com
}

\author{
James McCart \\ University of South Florida \\ 4202 E. Fowler Avenue, CIS 1040 \\ Tampa, FL 33620 \\ $+18139746765$ \\ jmccart@usf.edu
}

\begin{abstract}
The paper presents an agent-based modeling approach for the analysis of liquidity in corporate bond markets. Bond market liquidity is hard to measure empirically and its evolution is hard to predict due to its non-linear nature, with significant feedback loops between asset, funding and collateral markets. We discuss the applicability of agent-based modeling and present an initial model using a stylized market microstructure.
\end{abstract}

\section{CCS Concepts}

- Applied Computing Economics

\section{Keywords}

Agent-Based Modeling; Corporate Bond Market; Liquidity Risk; Systemic Risk

\section{INTRODUCTION}

Corporate bonds - transferable debt securities issued by companies - are an important means by which companies fund their business operations and expansion. Well-functioning bond markets - the mechanisms that connect bond issuers with investors and enables trading between investors - are deemed essential for economic activity and growth.

Following the financial crisis of 2008, corporate bond markets have experienced significant change as the combined effects of monetary policy, regulatory reform and changing business models took hold.

Persistent low yields caused the market to expand significantly (US corporate debt increased from 5.2 trillion (2007) to 8.1 trillion (Q2 2015)). The declining rate environment herded investors into similar positions (or "crowded trades") leading to a significant decrease in investor heterogeneity.

Collective investment vehicles (mutual funds, exchange traded funds, and others) witnessed extra-ordinary growth and have become significant players in corporate bond markets. In addition to the pro-cyclical effects of their homogenous investing styles, the potential imbalance between the immediacy of fund redemptions and the liquidity of the fund's bond holdings is a growing source of concern.

Dealer intermediation capacity has fallen significantly. Different from equities, in which trading takes place on exchanges (and other

Permission to make digital or hard copies of all or part of this work for personal or classroom use is granted without fee provided that copies are not made or distributed for profit or commercial advantage and that copies bear this notice and the full citation on the first page. Copyrights for components of this work owned by others than ACM must be honored. Abstracting with credit is permitted. To copy otherwise, or republish, to post on servers or to redistribute to lists, requires prior specific permission and/or a fee. Request permissions from Permissions@acm.org. DSMM'16, June 26-July 01 2016, San Francisco, CA, USA (C) 2016 ACM. ISBN 978-1-4503-4407-4/16/06...\$15.00 DOI: http://dx.doi.org/10.1145/2951894.2951898 multilateral facilities), corporate bonds are mostly traded through bilateral negotiation in decentralized over-the-counter (OTC) markets. Rather than transact directly amongst themselves, corporate bond investors typically trade with a network of brokerdealers, who execute the majority of customer transactions in a principal capacity. Recently, dealers have significantly decreased their commitments to making markets in corporate bonds as evidenced by the decline in dealer corporate bond holdings (see Figure 1), leading to a potential imbalance between market size and the trading channel.

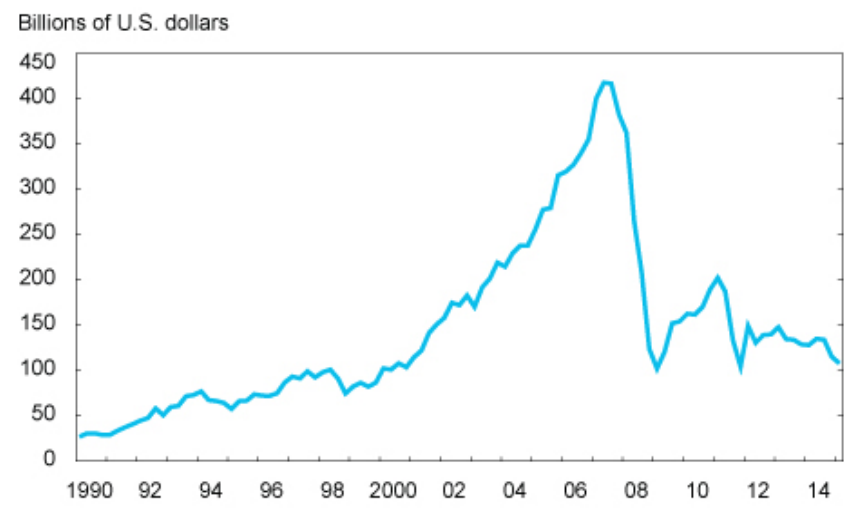

Source: Federal Reserve Board, "Financial Accounts of the United States." Note: The chart shows the quantity of corporate and foreign bonds (held in the United States) owned by securities brokers and dealers.

\section{Figure 1: Dealer Corporate Bond Holdings}

Over the past year, concerns around potential imbalances in the corporate bond markets have dominated discussions among market practitioners and regulators, with some observers arguing that the lack of liquidity in bond markets may trigger the next systemic risk event (see for example "The Liquidity Time Bomb," Roubini (2015)). While there is no universally accepted definition of liquidity, conceptually it can be thought of as the ability to buy or sell a given quantity of bonds, with reasonable immediacy, at low cost, without triggering an outsize impact on price.

\section{ANALYSIS OF LIQUIDITY UNDER STRESS}

While regulators and market participants have repeatedly voiced concerns around liquidity in corporate bond markets, opinions differ with respect to the magnitude of the perceived problem, its underlying causes and potential fixes.

In his speech to participants at the 4th Annual Fixed Income Conference at the University of South Carolina, Securities and Exchange Commission (SEC) Commissioner Piwowar addressed the issue of bond market liquidity and noted that "these are the 
types of issues that merit further study by academic researchers, and which would be of enormous value to the SEC and other financial regulators."

Investigations of liquidity have mostly focused on the evolution of liquidity indicators (such as the bid-ask spread, the difference in price dealers are willing to buy and sell a given bond) over historical time periods. These measures don't address the fact that crises exhibit dynamics that are not reflected in the day-to-day variations of pre-crisis times. In a 2013 working paper from the Office of Financial Research (OFR), Bookstaber et al. discuss the need for a "Version 3.0" of risk management, "... one that takes stress testing beyond the first-round effect of a shock to the individual financial institutions to ask: After the various institutions face the stress-induced losses, then what? How does that in turn alter the behavior of the banks and other market participants? How does the stress event play out and affect other parts of the financial system? Answering these questions requires a rethinking of the models in order to encompass the internal workings of the financial system ..."

The analysis of market liquidity lends itself to simulation approaches, since liquidity is typically ample in normal (steady state or equilibrium) market operation but tends to evaporate under conditions of stress. As part of the Granular Systemic Risk Project (GSRisk.org), we are therefore applying agent-based modeling to gain an understanding of the dynamics of liquidity under stress. Some of the specific questions we look to analyze using agentbased modeling include the following.

What are the conditions under which mutual fund outflows trigger fire sales? A general concern across market participants relates to the impact of rising interest rates on bond mutual funds. Since fund inflows and outflows tend to follow returns, rising interest rates (and falling bond prices) are widely expected to prompt significant outflows, causing funds to sell bond holdings in order to pay out redemptions. This may trigger a negative feedback loop or "fire sale" causing further downward pressure on price, affecting other market participants (e.g. margin-induced forced selling by leveraged investors) and causing even more downward pressure on price.

What are the effects of proposed liquidity risk regulations on mutual funds? Recognizing the potential misalignment between the liquidity of a fund's holdings and its redemption policy, the Securities and Exchange Commission proposed new regulations that could significantly affect market functioning (for example, see proposed SEC rule $22 \mathrm{e}-4$, addressing liquidity concerns in openend mutual funds and ETFs). We look to simulate the impact of such proposed regulations on market liquidity.

What are the effects of new capital constraints on various market participants? For example, new Basel III regulatory capital rules are likely to affect dealer banks.

What are the effects of new potential policy variables? The introduction of a floor (lower limit) on haircuts in secured financing transactions (or otherwise limiting the amount of leverage in the system) could be a potential new variable.

What are the effects of new trading venues and protocols? The private sector is responding with a multitude of new marketplace initiatives (some example initiatives include Electronifie, Trumid, Liquidnet FI, MarketAxess all-to-all trading, BondChain, Deplhx, MTS B2Scan, and Algomi Honeycomb). As new trading protocols and technologies get introduced, the marketplace could undergo significant structural change.

\section{AGENT-BASED MODELING}

Traditional approaches to micro-prudential risk management (including stress tests and portfolio risk analytics such as Value-atRisk) focus on the resilience of individual agents to specific shocks. They fail to address the broader question of how stress might be transmitted among firms through the dynamics of contagion and fire sales. Agent-based modeling however can capture the second order effects of interactions and feedback loops as it models the reaction functions (or behavior) of individual agents. It is particularly well suited to the analysis of the endogenous nature of liquidity dynamics under stress.

The Office of Financial Research published various papers discussing the value of $\mathrm{ABM}$ in the analysis of financial systemic risk, for example see Bookstaber (2012). Furthermore, the European Commission sponsored a major research initiative (CRISIS, the Complexity Research Initiative for Systemic Instabilities), which aims to analyze systemic risks to the financial sector and the wider economy using ABM. As noted in Farmer (2012), agent-based approaches have not been applied nearly as widely as DSGE (dynamic stochastic general equilibrium) and econometric models (see Figure 2).

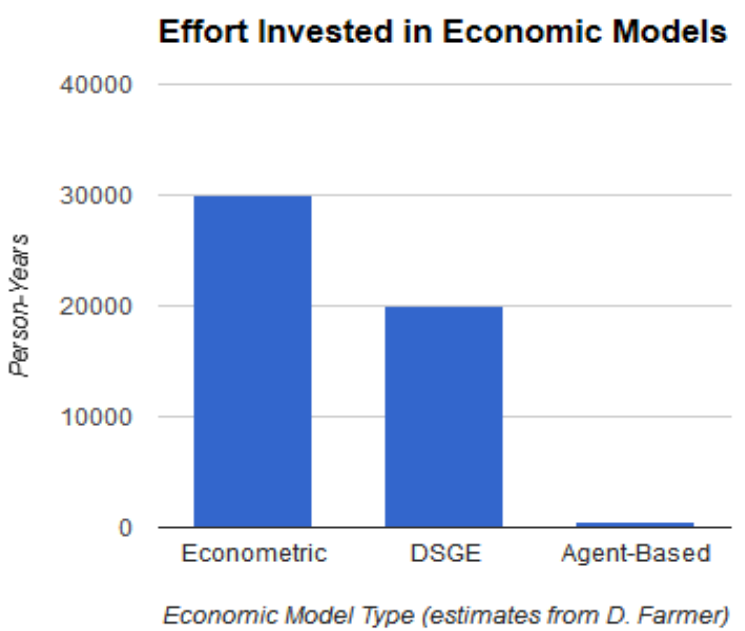

Figure 2: Economic Model Types

While most of the existing literature around the application of ABM to finance is focused on equity markets (with some interesting applications to currency and housing markets), we aim to analyze the liquidity conundrum in the corporate bond market using ABM, with specific focus on the research questions outlined in above.

\section{BOND MARKET MICROSTRUCTURE}

In reviewing bond market microstructure, we held informal discussions with several market participants, including major investment-grade issuers and buy-side participants. As we work on iterations of our agent-based models, we plan to intensify and formalize our outreach to market participants in order to validate inputs to our model and syndicate results.

Recent analysis from the Office of Financial Research highlights the importance of financial networks in understanding systemic risk and presents a model of the financial system as a multilayer network (see Figure 3). In line with this multilayer network view, we incorporated elements of the funding and collateral layers - in addition to the asset layer itself - into our initial market model.

The funding layer focuses on the role of leverage and its impact on fire sales (including feedback loops and cross-asset contagion). It 
includes critical constraints for leveraged market participants (such as hedge funds and broker/dealers).

In the collateral layer, the model assumes limited constraints on the availability and flow of collateral. All bonds in the experimental market are available as collateral against secured financing transactions and can be borrowed for delivery against short sales. The model furthermore includes security-specific haircuts, which can be adjusted by the lenders.

In addition to the three layers of the bond market, the model includes a few direct and indirect linkages with other asset verticals, including equities and government bonds. Equity markets impact the model through the behavior of one of the buy-side agents (an insurance company) that rebalances positions between equities and bonds based on equity market volatility (as well as absolute yield levels). Government bond markets furthermore provide the "risk free" yield curve, which is used as an input to the bond pricing equation.

The bond market agent-based model implements a somewhat stylized investor ecology, with participants trading a limited universe of bonds through broker/dealers (there is no direct trading between investors). Broker/dealers provide immediacy services on a principal basis (dealers cannot handle orders in an agency capacity) using a request-for-quote (RFQ) protocol.

While our overall goal for the initial market model is simply to verify that realistic market behaviors emerge from the interactions between agents with succinctly defined internal rules, the design already incorporates the essential elements of contagions and feedback loops.

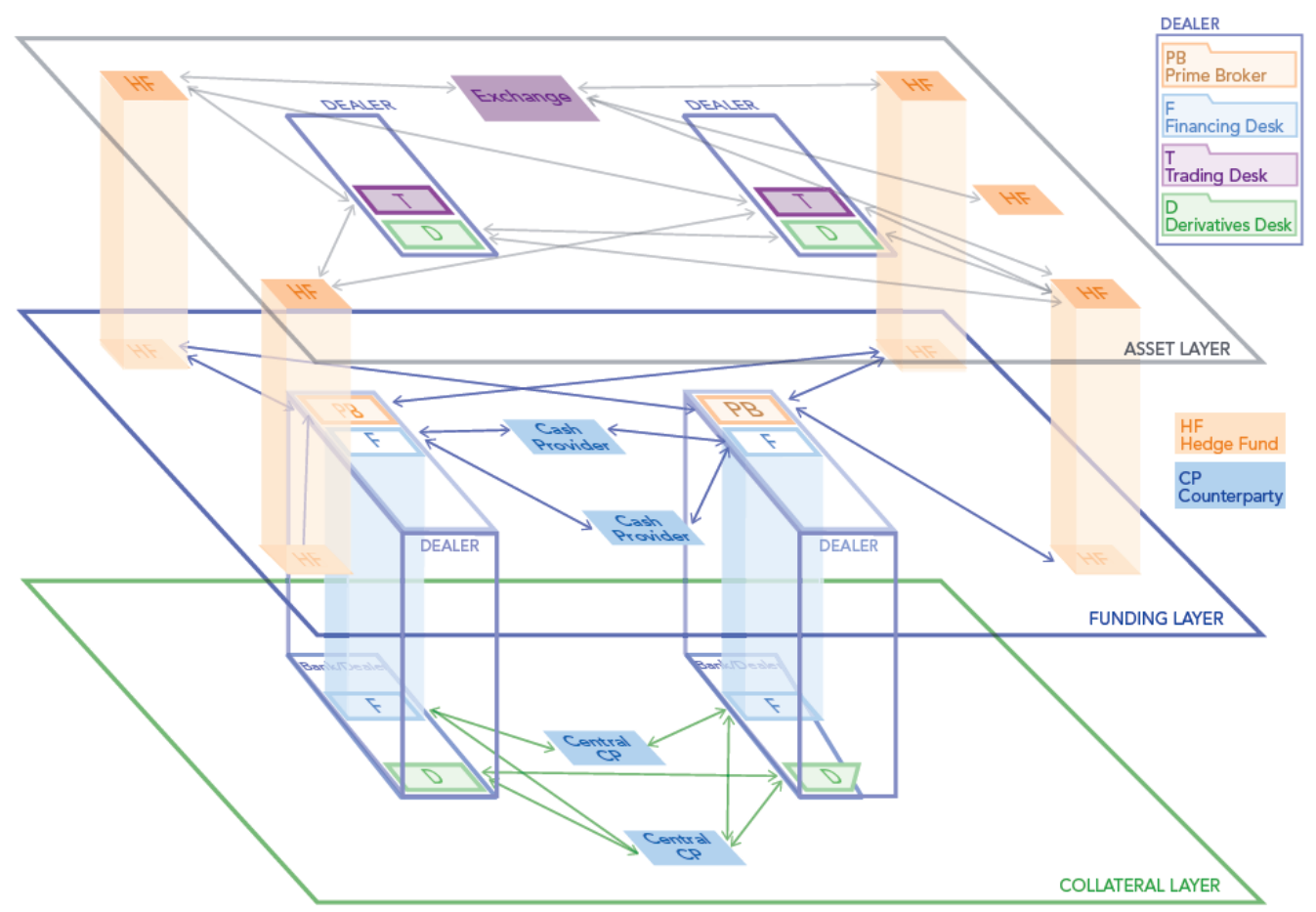

Figure 3: The Financial System as a Multilayer Network (Source: Office of Financial Research, 2015 Annual Report to Congress)

\subsection{Investor behavior (Buy-Side Agents)}

The market model includes three buy-side agents representative of a mutual fund, an insurance company and a hedge fund. In selecting the set of agents we aim to model representative corporate bond investor heterogeneity. While there are multiple ways to segment the investor base, we guided our selection of buy-side agents by the nature of their liabilities (leveraged versus nonleveraged, presence of inflows/outflows) and their investment mandate (passive versus active, long only versus long/short). The agents manage towards different investment horizons as highlighted in Figure 4.

Out of the three types of buy-side agents, two represent "real money" investors (using no leverage), while the third maintains leveraged positions. Real money investors cannot maintain short positions ("long only"); they include a pension fund (typical value investor) and a mutual fund (using passive index tracking). The leveraged investor represents an unconstrained participant (such as a hedge fund) that can maintain long and short positions. Model 0: Agents

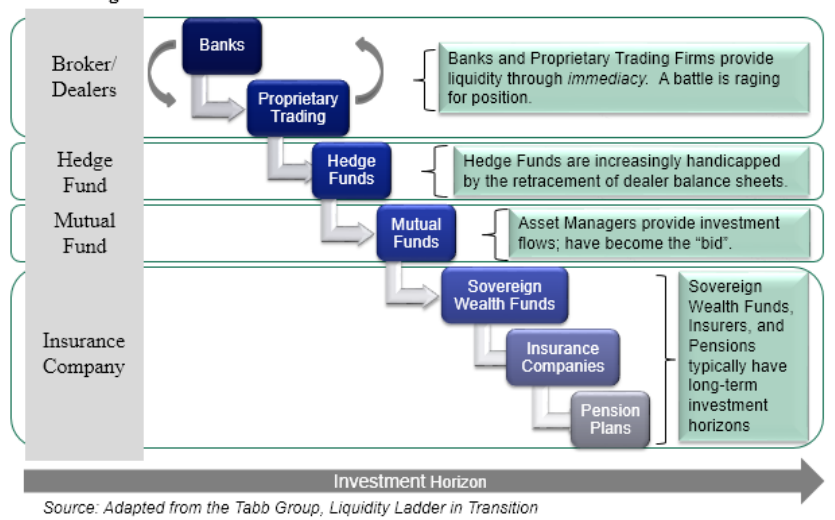

Figure 4: Model Agents (Adapted from the Tabb Group, Liquidity Ladder in Transition) 


\subsubsection{Mutual Fund}

The mutual fund acts as a real money investor who aims to replicate the performance of a defined benchmark. As noted, the fund is long only and does not leverage positions.

The fund's benchmark index includes the full universe of bonds available in the initial model and assumes static index weights (no periodic re-balancing of the index). The fund also maintains a dynamic cash balance as a buffer against investor redemptions (limiting forced sales) and to minimize transaction costs by parking cash until sizable orders can be made. The cash balance is managed to a target cash-to-assets ratio of 5\% with a lower bound of $3 \%$ and an upper bound of $8 \%$. Any dividends or capital gains distributions are assumed to be re-invested.

In this constellation, the mutual fund's trading activity is entirely driven by fund inflows and outflows, which in turn are primarily driven by the historical performance of the fund. As new money is invested, the mutual fund must put that money to work by buying bonds based on a pre-defined index. In the opposite direction, the mutual fund must liquidate a portion of the portfolio to meet redemptions that cannot be paid out of the available cash balance.

We keep track of the agent's wealth (Wt) in order to calculate historical returns over select time periods (returns are a key driver of fund inflows and outflows). We furthermore keep track of the fund's cash balance, given its critical role as a buffer against redemption risk. Wealth and cash balances are calculated as:

$$
\begin{gathered}
W_{t}=W_{t-1}+\text { NetContributions }_{t}+\text { Dividends }_{t} \\
+ \text { CapitalGainsLosses } \\
t
\end{gathered}
$$

with:

$W_{t}=$ Wealth at the end of period $t$

NetContributions $_{t}=$ Inflows $_{t}-$ Outflows $_{t}$

CapitalGainsLosses $_{t}=$ MarketValue $_{\text {bondst }}$

$$
\text { - MarketValue } \text { bonds }_{t-1}
$$$$
+ \text { Sales }_{t}-\text { Purchases }_{t}
$$

The cash position of the fund $\left(\mathrm{C}_{\mathrm{t}}\right.$ : cash at end of period $\left.\mathrm{d}_{\mathrm{t}}\right)$ can then be calculated as:

$$
\begin{aligned}
C_{t}= & C_{t-1} \\
& + \text { NetContributions }_{t} \\
& + \text { Dividends }_{t} \\
& + \text { Sales }_{t}-\text { Purchases }_{t}
\end{aligned}
$$

\subsubsection{Insurance Company}

The insurance company agent implements a long-term value investor with a liability driven investment strategy. This agent manages an investment portfolio across equity and fixed income markets and changes allocation between markets depending on overall market conditions.

The insurance company is a "long only" investor with additional constraints limiting the concentration of risk in any specific bond. In the initial model, leveraged positions cannot be established (another real money investor) and we further assume there are no external inflows or outflows in the form of premiums or claims.

Trading activity for the insurance company results from changes in portfolio allocation between equity and fixed income markets. Macro allocation decisions are driven by a number of variables, including equity market volatility as well as the current level and slope of the yield curve.

\subsubsection{Hedge Fund}

The hedge fund agent acts as a short-term tactical trader who follows a relative value trading strategy. As such the hedge fund maintains both long and short positions and makes active use of leverage. In the real world, fixed income relative value hedge funds have historically been among the most leveraged market participants.

The hedge fund agent is not subject to external inflows (basically a closed end fund) or redemptions (assume investor lock up); its trading capacity is constrained only by the availability of secured financing (leverage) from broker/dealer agents. We assume the hedge fund finances all positions on margin through primebrokerage style arrangements with some of the broker/dealers. Broker/dealers limit leverage using security-specific haircuts that can be dynamically adjusted depending on market conditions.

All margining is assumed to occur on an overnight basis. At the start of each trading day (a tick in the agent-based simulation), margin requirements are calculated based on current market prices and security-specific haircuts, as set by the broker-dealer agents. The difference between margin requirements and current wealth determines the trading capacity. If the new margin requirements exceed current wealth, the hedge fund is forced to liquidate positions (deleverage) to meet margin calls. Any excess wealth is free to be invested.

\subsection{Broker/Dealers and the RFQ protocol}

Broker/dealer agents only trade in response to requests from the buy-side agents. There is no inter-dealer market. Asset owners must trade with the broker/dealer offering the lowest price. The model includes three broker/dealer agents, each with somewhat of a specialization based on bond maturity (short term, medium term, and long term), though with overlapping ranges and the freedom to trade as desired. These dealers can maintain both long and short positions.

Broker/dealers are the price setters in our initial model. Dealer behavior is limited through regulatory constraints and market discipline, the latter expressed through a constraint on Value-atRisk (VaR) relative to capital.

Given the intent to trade, asset owners make a request-for-quote (RFQ) to all dealers. Dealers must respond with "no quote" or a full quote for the requested order size (no partial order fills are allowed). Requests are handled as follows:

- $\quad$ Request to sell (dealer buys): Dealer responds with "no quote" if their long position limit would be breached. If not, a full quote or bid is provided with a spread determined by the dealer's current position (including age of the inventory), the risk associated with a new position (based on factors affecting hedging costs), distance from any position limit, and price momentum (aligned with the notion that dealers avoid "catching a falling knife").

- $\quad$ Request to buy (dealer sells): Dealer responds with "no quote" if their short position limit would be breached. If not, a full quote or ask is provided with a spread determined by the factors described above, with an analysis that reverses much of the logic.

\section{MARKET UNIVERSE}

The market universe consists of five tradable bonds. The bonds are identical with respect to structure, form and major covenants including issuer, redemption (bullet redemption at maturity without 
optionality clauses) and rate provisions (fixed coupon). The bonds differ along only three dimensions:

1. Outstanding nominal amount ranges from $500 \mathrm{M}$ to $2 \mathrm{~B}$.

2. Maturities cover major points on the yield curve $(1,2,5$, 10 and 25 years).

3. Coupon rates range from $1.75 \%$ to $4.00 \%$.

Table 1. Tradable Bond Characteristics

\begin{tabular}{|l|c|c|c|c|c|}
\cline { 2 - 6 } \multicolumn{1}{c|}{} & bond 1 & bond 2 & bond 3 & bond 4 & bond 5 \\
\hline Nominal & $500 \mathrm{M}$ & $500 \mathrm{M}$ & $1 \mathrm{~B}$ & $2 \mathrm{~B}$ & $1 \mathrm{~B}$ \\
\hline Maturity & $1 \mathrm{Y}$ & $2 \mathrm{Y}$ & $5 \mathrm{Y}$ & $10 \mathrm{Y}$ & $25 \mathrm{Y}$ \\
\hline Coupon & $1.75 \%$ & $2.5 \%$ & $2.25 \%$ & $2.4 \%$ & $4 \%$ \\
\hline
\end{tabular}

\subsection{Asset Value Dynamics}

At any point in time, all asset owners (the "buy side") perceive the same fundamental value for a specific bond. That is, all asset owners use the same valuation model and observe the same input prices (maintaining homogenous beliefs). The value for the above five bonds is fully reflected in five data points (a par yield curve with five rates) and a simple calculation of any given bond's price given its par yield. The asset owners' assessment of value changes over time based on the supply and demand for each bond and exogenous factors such as monetary policy.

\subsection{Starting Conditions (Time Zero)}

The starting conditions for the agent-based simulation include:

- Bond index composition with (static) weights based on nominal amount (Table 2. Bond Index Composition).

- Initial par yield curve and bond prices (Table 3. Initial Yield Curve and Bond Prices).

- Bond positions are allocated to buy-side agents and dealers reflecting an overall split of $40 \%$ (mutual fund), $50 \%$ (insurance company) and 10\% (dealers). The mutual fund is invested across the 5 bonds based on the index weights. Maturity preferences and sector specialization drive the allocation of starting positions for the insurance company and the dealers. Table 4 summarizes the opening bond positions.

- Haircuts are set uniformly across all 5 bonds.

In addition, initial endowments for the buy-side agents include:

- Mutual fund: In addition to its bond holdings, the fund has an opening cash position reflecting a 5\% cash-toassets ratio.

- Insurance company: Initial portfolio allocation includes a 60/40 split between fixed income and equity markets (assumed to be invested in a broad market index like the S\&P 500).

- Hedge fund: Initial equity (held as cash) is $150 \mathrm{M}$. The opening equity position is set to ensure leverage constraints (using realistic haircuts) become binding after accumulating a specific market share.

Table 2. Bond Index Composition

\begin{tabular}{|l|c|c|c|c|c|}
\cline { 2 - 6 } \multicolumn{1}{c|}{} & bond 1 & bond 2 & bond 3 & bond 4 & bond 5 \\
\hline Nominal & 500 & 500 & 1000 & 2000 & 1000 \\
\hline Index weight & $10 \%$ & $10 \%$ & $20 \%$ & $40 \%$ & $20 \%$ \\
\hline
\end{tabular}

Table 3. Initial Yield Curve and Bond Prices

\begin{tabular}{|c|c|c|c|c|c|}
\hline \multirow{2}{*}{ Yields } & $1 \mathrm{Y}$ & $2 \mathrm{Y}$ & $5 \mathrm{Y}$ & $10 \mathrm{Y}$ & $25 \mathrm{Y}$ \\
\cline { 2 - 6 } & $1.50 \%$ & $1.75 \%$ & $2.50 \%$ & $2.60 \%$ & $4.21 \%$ \\
\hline \multirow{2}{*}{ Prices } & bond 1 & bond 2 & bond 3 & bond 4 & bond 5 \\
\cline { 2 - 6 } & 100.247 & 101.468 & 98.832 & 98.249 & 96.772 \\
\hline
\end{tabular}

Table 4. Opening Bond Positions

\begin{tabular}{|l|c|c|c|c|c|}
\cline { 2 - 6 } \multicolumn{1}{c|}{} & bond 1 & bond 2 & bond 3 & bond 4 & bond 5 \\
\hline Mutual F. & 200 & 200 & 400 & 800 & 400 \\
\hline Ins. Cpy. & 0 & 250 & 500 & 875 & 500 \\
\hline Hedge F. & 0 & 0 & 0 & 0 & 0 \\
\hline Dealer 1 & 300 & 50 & 0 & 100 & 0 \\
\hline Dealer 2 & 0 & 0 & 50 & 125 & 0 \\
\hline Dealer 3 & 0 & 0 & 50 & 100 & 100 \\
\hline
\end{tabular}

\subsection{Preliminary Model Performance}

Two of the challenges in agent-based modeling are: 1) to ensure that the approach is a good fit to the problem and 2) that the agentbased model is rigorously applied.

As noted above, due to their endogenous risk characteristics, financial markets provide a natural fit for agent-based models and simulation.

Rand and Rust (2011) propose guidelines for rigor in agent-based modeling that can be used to organize this research into issues of verification and validation.

Verification focuses on how well the agent-based model corresponds to the conceptual model. Documentation, programmatic testing (such as unit testing and code walkthroughs), test cases and scenarios are all useful tools for verification. The corporate bond market model used in this research was fully specified at a detailed level, with each agent implementation grounded in the financial research literature. In addition, unit testing, code walkthroughs, and model-level test cases have been used during development.

Validation assesses how well the agent-based model corresponds to reality. Tools here include micro-face validation, macro-face validation, and empirical testing. Micro-face validation looks at how well individual elements of the model correspond "at face value" to the real world. Again, each agent was specified and implemented using key factors identified in the financial literature. Macro-face validation considers how well "processes and patterns" correspond to the real world. The bond market model implements bilateral trading arrangements based on a request-for-quote (RFQ) mechanism, mirroring the real bond market. With regard to patterns, simple exogenous shocks based on actual events, such as quantitative easing, are being used to assess how well the model responses correspond with real world events. Finally, empirical validation can be used to assess how the model corresponds to both real world input and output data. The model is being validated using historical input data, such as interest rates and equity prices, along with comparisons based on the bond trading activities and prices as output.

As an example, experiments based on trading patterns have been used as part of the micro-face validation of the mutual fund agent. Recall that the basic mutual fund agent trades only in response to inflows and outflows (from investors). The mutual fund buys and 
sells using an index-following behavior; so additional funds are allocated across the available bonds according to static index weights. Investor outflows force liquidations, again across the bond index. A cash balance is maintained to cushion against outflows, as well as make new investments in meaningful amounts. Therefore, the cash-to-assets ratio is a reasonable metric for assessing mutual fund agent behavior. Mutual fund agent cash-toassets ratios vary between $3-8 \%$ of the portfolio value (excluding cash), with an optimal target of 5\%. Prolonged periods of inflows or outflows should drive the cash-to-assets ratio in a single direction. As an experiment, four distinct phases were simulated. Phase 1 had small randomly generated inflows and outflows (in the symmetrical range of $+/-1$ million dollars) that should have resulted in small changes in the cash-to-assets ratio (see Figure 2). The second phase had larger inflows and outflows (+/- 10 million dollars) that resulted in correspondingly larger swings in the cashto-assets ratio.

The next two phases had asymmetrical ranges that generated either more inflows or outflows. In the case of inflows, the expectation would be that the continued addition of funds would cause repeated cycles of new investment, cushioned by the buildup of cash. Outflows would result in a similar pattern of repeated liquidations, again cushioned by cash reserves. As seen in Figure 5, the last two phases have distinctive "saw tooth" patterns. Phase 3 had randomly generated inflows and outflows, skewed toward outflows (in the range -10 to +2 million). These investor redemptions forced the mutual fund to deplete cash reserves until repeated liquidation events became necessary for the continued servicing of outflows. The cycle of cash depletion and liquidations to replenish the reserves is quite apparent. Similarly, in phase 4 the situation is reversed with randomly generated inflows and outflows (in the range of -2 to +10 million) giving rise to more inflows. Continued inflows result in cash reserves repeatedly reaching a point that requires new investment based on the benchmark index. Each investment draws down cash, which then builds up again over time. The last panel in Figure 5 clearly shows a similar cyclical pattern. These types of experiments are being used to validate the agent behaviors in our preliminary model.

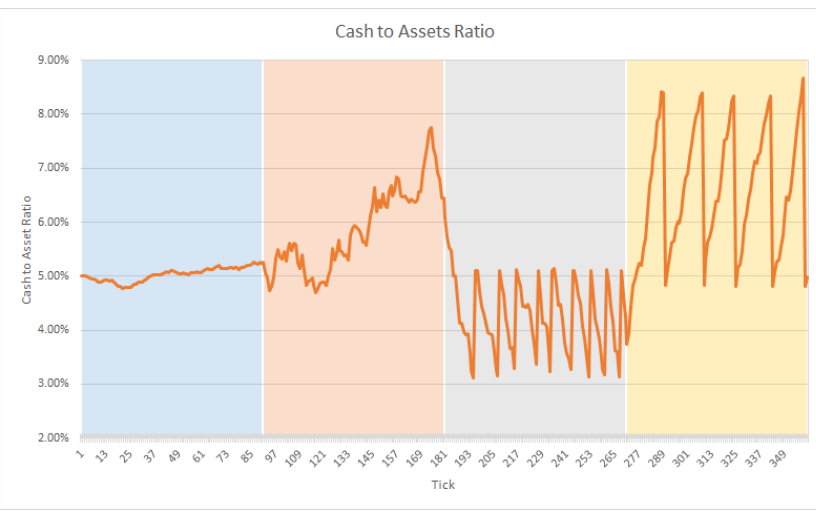

Figure 5. Mutual Fund Cash-to-Asset Ratio Changes

\section{CONCLUSION}

In this paper, we introduce an agent-based model of the corporate bond market.

The model includes three buy-side agents that provide a nice breadth of different investment approaches and make even this minimal initial model fairly realistic. The sell-side agents include three broker/dealer agents who serve as the price setters in the model, responding to request-for-quote (RFQ) messages from the buy-side agents. This simple six-agent model is being used to refine agent behaviors and assess the model response to basic exogenous factors (such as monetary policy) and the introduction of regulatory constraints on investor behavior.

\section{ACKNOWLEDGMENTS}

The National Science Foundation (NSF Award 1445403) and the Office of Financial Research (OFR) have funded this research. For more details, please see the project website at GSRisk.org.

\section{REFERENCES}

[1] Ang, A., Gorovyy, S. and van Invwegen, G. B. 2011. Hedge Fund Leverage. Journal of Financial Economics Vol. 102(1): 102-126. (Oct. 2011) DOI= http://dx.doi.org/10.3386/w16801

[2] Bookstaber, R., 2012. Using Agent-Based Models for Analyzing Threats to Financial Stability. Office of Financial Research Working Paper \#0003 (Dec. 2012)

[3] Bookstaber, R., Cetina, J., Feldberg, G., Flood, M. and Glasserman, P. 2013. Stress Tests to Promote Financial Stability: Assessing Progress and Looking to the Future. Office of Financial Research Working Paper \#0010 (Jul. 2013)

[4] Brunnermeier, M. K. and Pedersen, L. H. 2009. Market Liquidity and Funding Liquidity. Review of Financial Studies Vol. 22 Issue 6: 2201-2238 (2009). DOI= http://dx.doi.org/hhn098

[5] Chen, Y. and Qin, N. 2015. The Behavior of Investor Flows in Corporate Bond Mutual Funds. Management Science, Forthcoming. DOI= http://dx.doi.org/10.2139/ssrn.2022059

[6] Committee on the Global Financial System (CGFS). 2011. Fixed Income Strategies of Insurance Companies and Pension Funds. CGFS papers No. 44.

[7] Edwards, A. K., Harris, L. and Piwowar, M. S. 2007. Corporate Bond Market Transaction Costs and Transparency". Journal of Finance, Vol. 62, No. 3 (Jun. 2007), DOI= http://dx.doi.org/10.1111/j.15406261.2007.01240.x

[8] Farmer, J. D. 2012. The agent-based modeling approach to MFM: A call to join forces. Presentation at the Macroeconomic Financial Modeling meeting (Sep. 2012)

[9] Flood, M. D., Liechty, J. C., Piontek T., Systemwide Commonalities in Market Liquidity. Office of Financial Research Working Paper (May 2015)

[10] Goldstein, I., Jiang, H. and Ng, D.T. 2015. Investor Flows and Fragility in Corporate Bond Funds. Working Paper. DOI= http://dx.doi.org/10.2139/ssrn.2596948.

[11] Office of Financial Research, 2015 Annual Report to Congress (Jan. 2016)

[12] Rand, W. Rust, R. 2011. Agent-Based Modeling in Marketing: Guidelines for Rigor. International Journal of Research in Marketing, 28: 181-193 (Jun. 2011).

[13] Roubini, N. 2015. The Liquidity Time Bomb. Available online at https://www.projectsyndicate.org/commentary/liquidity-market-volatility-flashcrash-by-nouriel-roubini-2015-05 